\title{
MEADOWS, DONELLA; RANDERS, JORGEN Y MEADOWS, DENNIS, Limits to Growth: The 30-Year Update. Chelsea Green, 2004.
}

\begin{abstract}
¿Puede un método sistémico computacional ser útil para la investigación y la intervención social? Esta pregunta subyace a la reciente actualización del Informe al Club de Roma, Los límites del crecimiento (1972). Para los autores, depende de la significatividad y exactitud de lo que, desde su personal visión del mundo, infieran del diseño y los resultados del modelo (aquí, World3-03), si bien, ante todo, los autores enfatizan que nunca, ni en 1972, ni en Beyond the Limits (1992), ni ahora, han hecho predicciones.

La dinámica social a gran escala es demasiado compleja para modelarla por adelantado con una precisión útil y, además, los resultados deben reintroducirse como datos - capacidad iterativa de aprendizaje social - y el efecto de ese bucle, la imprevisible creatividad humana, es imposible de modelar. Aún así, un modelo puede ser útil si representa, aunque sea a grandes rasgos, la conducta de un sistema cuyas propiedades clave incorpora con realismo. La estructura básica de World3 se reduce a tres rasgos:
\end{abstract}

(1) Sus variables centrales - población y transumo (cantidad de materia y energía procesadas)-, tienden a crecer exponencialmente: el modelo integra la teoría de la transición demográfica, de modo que mejoras en los servicios de salud y educación reducen la mortalidad y la natalidad (y la prosperidad el tamaño de las familias) y la población tiende a estabilizarse; en cambio, el crecimiento del uso de recursos no tiene más obstáculo que su disponibilidad y la capacidad de absorción de los sumideros.

(2) Hay límites físicos al crecimiento, dados por el rendimiento decreciente de las fuentes de recursos no renovables, la explotación insostenible de los renovables y la saturación de los sumideros. Los límites son dinámicos: pueden elevarlos el hallazgo de nuevos recursos o reservas, la invención de tecnologías material o energéticamente más eficientes o la moderación de las metas de proceso-consumo; y los reduce rebasarlos erosionando la mecánica homeostática que sustenta su capacidad de absorción o regeneración.

(3) Hay demoras en el flujo de información -entre las fases de aparición de los primeros signos, admisión y comprensión del problema, diseño, implementación, evaluación, selección y difusión de respuestas que se conviertan en rasgo general del sistema, y valoración de sus efectos-; por eso el sistema responde con cierto retraso a sus desequilibrios.

Este modelo tiene cuatro conductas posibles. El sistema (1) puede crecer indefinidamente si sus límites crecen a una tasa igual o menor; (2) se acomoda a sus límites si los percibe a tiempo y responde con rapidez y acierto - si los signos se malinterpretan, tergiversan, ignoran o niegan o si la respuesta es errada o tardía, sucede el rebasamiento-; (3) se equilibra con la capacidad de carga tras alguna oscilación si los límites no sufren daño grave al ser temporalmente rebasados o se auto-restauran pronto; (4) se ajusta a los límites, cuando estos se deterioran irreversiblemente, mediante un colapso que reduce su dimensión y dinámica a lo sostenible, provisionalmente, en el nuevo entorno degradado. Al introducir en el modelo, a efectos de simulación, datos reales sobre demografía, usos y producti- 
vidad de la tierra, producción industrial y de servicios o polución, con mucho el resultado más frecuente es, obviamente, el colapso.

En 1972 la idea de límites del crecimiento fue comúnmente recibida con indignado escepticismo, pese a afirmar que el crecimiento duraria hasta 2015 incluso en el peor escenario y que eso ofrecía tiempo y recursos para evitar el rebasamiento. En 1992, en vísperas de la Cumbre de la Tierra, Más allá de los límites expuso que la humanidad ya había topado con su primer límite global -la reducción de la capa de ozono- y había rebasado, a fines de los años ochenta, la capacidad de carga terrestre. Mostraba también que los cambios de las décadas previas apenas alteraban sus escenarios: el colapso seguía siendo el caso más probable, aunque evitable todavía con los medios disponibles. Pero intereses egoístas individuales, empresariales y nacionales desperdiciaron también la década que culminó en la Cumbre de Johanesburgo (2002).

Los autores han debido reconocer que mientras su adversario sistémico, el 'libre' comercio - potenciador del crecimiento indiscriminado y globalizador de sus externalidades-, es hoy una noción popular y la esencia de un ente como la Organización Mundial de Comercio, los conceptos de límite, rebasamiento y transumo -ni mentar colapso- aún son tecnicismos mal recibidos en los altos despachos. Y eso pese a titulares de prensa casi diarios referidos a evidencias de rebasamiento, como la reducción de reservas de recursos, el aumento de la emisión de residuos nucleares, tóxicos y peligrosos, mayores costes de abastecimiento y mantenimiento del capital, persistencia de la pobreza extrema, crisis de legitimidad de élites tachadas de «incompetentes» y «egoístas" y aumento de las catástrofes «naturales» atribuibles al segundo, y acaso definitivo, gran límite global que afrontamos, el cambio climático por aumento del efecto invernadero derivado principalmente de la combustión insostenible de combustibles fósiles.

Así pues, insistir en la creciente probabilidad del colapso no sirve; la idea se pierde entre tantos mensajes alarmistas de colectivos que se victimizan con más o menos justificación. Por eso, este informe intenta precisar ideas que contribuyan a «la Revolución de la Sostenibilidad» - un salto sociotécnico orgánico análogo a la Revolución Neolítica, que superó los límites locales de las sociedades de cazarecolección, o a la Revolución Industrial, que lo hizo con las sociedad agrariaPara ello se esfuerza en refinar y aclarar sus afirmaciones; distinguir bien escenarios imposibles, plausibles y deseables; dar el máximo valor a la variable 'tiempo'; y mostrar grosso modo la vía de transición a una sociedad ecológicamente sostenible y materialmente suficiente y equitativa.

World 3 sugiere estrictamente que graves constreñimientos ecológicos globales -ligados al aumento de la población, el uso de recursos y la emisión de contaminantes- incidirán en el desarrollo social a lo largo del siglo XXI. En el pasado, olas sucesivas de innovación técnica revertieron la tendencia del sistema a los rendimientos decrecientes del capital, siempre gracias a un crecimiento exponencial del transumo de energía, materias primas y trabajo. Esa opción es cada vez menos accesible porque debe desviarse cada vez más capital a combatir las constricciones ecológicas -menos recursos, sumideros rebosantes, daños y población crecientes-. La inversión no podrá mantener la producción industrial, ni ésta la de alimentos, servicios, etc. El nivel de vida medio caerá y el crecimiento demográfico se revertirá.

Este escenario fatal es inverosímil porque no incorpora ningún cambio en la 
producción y el consumo en presencia de la catástrofe, pero es el resultado del modelo por defecto. Igualmente imposible es el popular escenario de crecimiento material indefinido sin cambiar casi nada. Mucha gente quiere creerlo porque esperan de él los recursos para la innovación técnica y la movilidad social ascendente, para aumentar el bienestar, reducir la pobreza y proteger y restaurar el entorno - como en el pasado-.

Es inviable por tres causas: primero, los límites físicos (no monetarios) del sistema impiden rebasar la capacidad de carga sin colapsar - salvo si se retrocede a tiempo; o si los límites se amplían, pero ocurre lo contrario-; segundo, el mecanismo sistémico inherente de motivación y recompensa hace que los diferentes beneficios que se reproducen y acumulan exponencialmente como riqueza y pobreza tiendan a reforzarse - en potencia, estadísticamente y en ausencia de mecanismos sociales de redistribución, como la población o el capital industrial--, esto es, el sistema, por sí solo, tiende a aumentar la diferencia entre (individuos, negocios, países) ricos y pobres, no a reducir la pobreza; y tercero, más grave aún, si el crecimiento no supone más bienestar y libertad para las mujeres, si éstas no tienen alternativas educativas ni más opción de inversión que sus hijos, la transición demográfica se atasca en su fase de gran diferencia entre natalidad y mortalidad, arrastrando a millones a una masacre malthusiana.

El fin del crecimiento económico indiscriminado sucederá inevitablemente, pero que ocurra un desplome o un suave ajuste de la huella ecológica a la capacidad de carga planetaria, depende de nuestras decisiones y nuestra diligencia. En los escenarios plausibles, los autores añaden -bajo parámetros temporales y de costes de la innovación sociotécnica verosímiles - mejoras que prolongan la prosperidad y posponen unas décadas el colapso (por crisis de agotamiento de recursos no renovables, de polución global, producción de alimentos, erosión de la tierra o costes de capital). Pero hay una fórmula que permite un equilibrio viable a más de una generación vista. Es un escenario doblemente optimista.

Primero - por dificultad de operacionalización-, World 3 no tiene una esfera social «realista»: no hay conflicto, corrupción, desastres naturales, pandemias ni "sorpresas" ambientales; rebosa estabilidad y seguridad; su liderazgo es honrado, con visión de futuro y abierto a nuevas ideas $\mathrm{y}$ valores, $\mathrm{y}$ posee firmes bases institucionales para un avance técnico constante y apropiado, pues mercados y estados deciden sin costes ni demoras, las tecnologías no tienen externalidades negativas y no se desvía capital al sector militar. Más aún, no incluye diferencias entre regiones o estratos ricos y pobres -que suelen ignorar los problemas de otros, salvo que les afecten vía la creciente globalización-; no hay efectos dominó a partir de colapsos locales.

Sobre esto, dobla la eficiencia técnica y los recursos no renovables disponibles respecto a la estimación actual, implementa un formidable programa de ecoeficiencia con tecnologías ahorradoras de recursos, de control de la polución, intensificación (convencional) de la fertilidad del suelo y optimos métodos (gratuitos) contra la erosión; y a esta exaltada visión del poder de la técnica y la capacidad adaptativa del mercado añade cambios es. tructurales en los flujos de información del sistema: asume como conductas actuales una fecundidad de equilibrio estable, limitación voluntaria general a un nivel de vida suficiente y una actitud productiva y de consumo inclinada a los bienes duraderos.

Este escenario 'ideal' permite concluir que la transición a la sostenibilidad aún es posible con los recursos y técnicas disponibles o previsibles, sin reducir la pobla- 
ción o la producción industrial y sin trastornar la estructura sociopolítica. Pero sí exige reducir la huella ecológica global mediante un uso industrial menor y más eficiente de los recursos y familias menores, estilos de vida menos materiales y más equitativos; y un doble esfuerzo por conservar, y hasta restaurar, fuentes y sumideros, y prevenir, retrasar y revertir la erosión; y por mejorar la investigación, detección y comprensión de señales de rebasamiento, la velocidad y acierto de la respuesta y la profundidad del horizonte de prevención y planificación - basados en análisis de costes y beneficios a largo plazo-.

Las propuestas de reducir el crecimiento también desatan debates sobre la distribución -del esfuerzo y de la responsabilidad-, pero es esperable que se actúe primero donde la eficiencia de la inversión es mayor: reducir el uso de materia y energía por persona en el Norte, atajar las emisiones por unidad de producto en las economías emergentes y limitar el crecimiento demográfico en el Sur. «El reto global -afirman los autores- puede enunciarse sencillamente: para alcanzar la sostenibilidad, la humanidad debe aumentar el niveles de consumo de los pobres del mundo al tiempo que reduce su huella ecológica total.»

Alarmantemente, la «ventana de oportunidad» para evitar el colapso se reduce con rapidez. La transición puede promoverse de mil modos pero cuanto mayores sean las cotas de población y nivel de vida material a que se aspire y cuanto más se demore la reducción de los transumos, más probable y pronto resulta el colapso y/o menores serán los recursos, las oportunidades, las opciones y el bienestar sostenible - base material de su libertad- de que dispondrán las generaciones futuras.

Los dos últimos escenarios modelados son idénticos al 'ideal' salvo en sus fechas de inicio. El resultado del primero
(1982) es un mundo populoso, limpio, próspero y sostenible a muy largo plazo; con más opciones, más libre que el actual y que cualquiera que podamos alcanzar ya hoy. El resultado del segundo (2022) es un súbito, profundo y turbulento colapso. De nuevo hay que subrayar que esto no es una predicción; es sólo una herramienta para refinar nuestros modelos mentales sobre el futuro. En medio hay un mundo posible porque las altas tasas actuales de transumo son innecesarias para dar un nivel de vida digno a todos los habitantes del mundo. Pero ya no hay tiempo para debates fútiles porque costará mucho lograr cambios en los valores individuales y en las políticas públicas y empresariales planificadas a largo plazo que inviertan las tendencias actuales.

¿Qué pueden aportar las ciencias sociales que ilumine las décadas inminentes de gran cambio social? Los autores creen que una sociedad sostenible no tiene porqué ser pobre, primitiva, estancada, depresiva, monótona, aburrida, centralizada, autoritaria, o sin desafíos. (Ni siquiera debe renunciar al crecimiento material y al uso de recursos no renovables -si desarrolla un sustitutivo sostenible, de preferencia más barato, sin desbordar su sumidero- según para qué, para quién, por cuánto tiempo y dentro de límites). Pero, ¿no lo será? ¿O sí? Y, ¿por qué no va a ser más probable la respuesta «recesiónrepresión/agresión» que ha dominado las crisis de la sociedad industrial desde su inicio? $\mathrm{O}$, más aún, ¿por qué no va a ocurrir una pérdida del $90 \%$ de la población y la reducción del sistema socio-productivo al nivel de subsistencia, como en la mayoría de los colapsos preindustriales que describe Jared Diamond en Collapse (2005).

La modelización de la dinámica social a gran escala y para periodos largos ha avanzado poco entre la breve síntesis de la Sociología Histórica ofrecida por Char- 
les Tilly en Grandes estructuras, procesos amplios, comparaciones enormes (1984) y los bocetos sobre ascenso y caída de los estados presentados Randall Collins en Macrohistory (1999). Peor aún, las principales teorías fracasan ante esta tesitura. ¿Qué puede decir la teoría normativa ante una crisis que exige cambiar las normas y las normas para evaluar las normas y...? ¿A qué hipótesis ad hoc recurrirá la teoría de la elección racional, con su «dificultad» para modelar la cooperación social, cuando ésta es la condición necesaria para evitar el colapso? La transición revolucionaria a la sostenibilidad requiere una eclosión masiva de creatividad, también en las ciencias sociales.

Juan Manuel Iranzo 